\title{
CORRECTION
}

View Article Online

View Journal I View Issue

\section{Correction: Epitaxial growth of GaN films on unconventional oxide substrates}

Cite this: J. Mater. Chem. C, 2014, 2, 10218

Wenliang Wang, ${ }^{a}$ Weijia Yang, ${ }^{a}$ Haiyan Wang ${ }^{a}$ and Guoqiang Li*ab

DOI: $10.1039 / \mathrm{c} 4 \mathrm{tc} 90149 \mathrm{e}$

Correction for 'Epitaxial growth of GaN films on unconventional oxide substrates' by Wenliang Wang et al., J.

www.rsc.org/MaterialsC

Mater. Chem. C, 2014, 2, 9342-9358.

Some of the parameters listed in Table 1 on the third page of this Feature Article were incorrect. The correct version of this table is given below with the revised values given in bold for clarity.

Table 1 Lattice parameters of unconventional oxide substrates and their epitaxial directions

\begin{tabular}{|c|c|c|c|c|c|c|c|}
\hline \multirow[b]{2}{*}{ Substrates } & \multicolumn{3}{|c|}{ Lattice parameters } & \multirow[b]{2}{*}{ Epitaxial direction } & \multirow[b]{2}{*}{ Lattice mismatch \% } & \multirow[b]{2}{*}{ Thermal mismatch \% } & \multirow[b]{2}{*}{ Ref. } \\
\hline & $a / \mathrm{nm}$ & $b / \mathrm{nm}$ & $c / \mathrm{nm}$ & & & & \\
\hline GaN & 0.3189 & 0.3189 & 0.5185 & {$[0001]$} & 0.0 & 0 & 11 \\
\hline Sapphire & 0.4760 & 0.4760 & 1.2991 & [0001] & 13.3 & 27 & 11 and 12 \\
\hline LSAT & 0.7730 & 0.7730 & 0.7730 & [111] & 1.0 & 3.6 & 13-15 \\
\hline $\mathrm{LiAlO}_{2}$ & 0.5169 & 0.5169 & 0.6260 & {$[100]$} & 0.3 & 21.3 & 16 and 17 \\
\hline $\mathrm{LiGaO}_{2}$ & 0.5402 & 0.6370 & 0.5007 & [001] & 0.2 & 16.6 & $18-20$ \\
\hline $\mathrm{LaAlO}_{3}$ & 0.3791 & 0.3791 & 0.3791 & [001] & 3 & 39.2 & 21 \\
\hline $\mathrm{MgAl}_{2} \mathrm{O}_{4}$ & 0.8083 & 0.8083 & 0.8083 & [111] & 9.0 & 37.9 & 22 and 23 \\
\hline $\mathrm{MgO}$ & 0.4210 & 0.4210 & 0.4210 & [111] & 7 & 56.3 & 24 and 25 \\
\hline $\mathrm{ZnO}$ & 0.3250 & 0.3250 & 0.5200 & [0001] & 0.4 & 7.6 & $26-28$ \\
\hline
\end{tabular}

Full details of the references cited in Table 1 can be found in the original article (DOI: 10.1039/c4tc01655f).

The Royal Society of Chemistry apologises for these errors and any consequent inconvenience to authors and readers. 